\title{
Sistem Informasi Booking Futsal Menggunakan Metode Agile SDLC Pada KAO Futsal
}

\author{
Ade Setiadi*1 \\ Ridhoi Ahmad Ridwan ${ }^{2}$ \\ Naufal Ridhwan Rizqullah ${ }^{3}$ \\ ${ }^{1,2,3}$ Program Studi Teknik Informatika Fakultas Sains dan Teknologi Universitas Raharja \\ E-mail: *1.
}

\begin{abstract}
Abstrak
Futsal adalah sebuah olahraga permainan bola yang dimana 1 (satu) team yang beranggotakan 5 (lima) orang. KAO futsal merupakan tempat sarana olahraga yang berada di kota Tangerang yang menyediakan tempat penyewaan permainan olahraga futsal. Sistem yang berjalan saat ini masih konvensional yaitu dengan melakukan pencatatan di buku besar. Guna mempermudah proses pemesanan penggunaan lapangan futsal maka dibuat penelitian untuk membuat Sistem Informasi Booking Futsal pada KAO futsal dengan menggunakan metode pengumpulan data dilakukan dengan cara observasi, studi pustaka, dan wawancara. Metode analisis sistemnya menggunakan analisis SWOT. Rancangan program ini dibuat menggunakan UML yang berisikan use case diagram, activity diagram dan sequence diagram sebagai alat design, dengan menggunakan Bahasa program PHP (hypertext preprocessor) berbasis framework Codeigniter dan MySQL sebagai database dengan menggunakan Metode Agile sebagai metode pengembangan sistem (SDLC). Metode untuk pengujian yang digunakan blackbox testing. Sistem informasi penyewaan lapangan futsal ini diharapkan dapat mempermudah customer dan pengelola lapangan futsal dalam proses pengelolaan jadwal pemakaian lapangan futsal.
\end{abstract}

Kata Kunci : booking, futsal, SDLC, agile.

\begin{abstract}
Futsal is a soccer game where 1 (one) team consists of 5 (five) people. Futsal KAO is a sports facility located in the city of Tangerang which provides a rental place for futsal sports games. The current system is still conventional, namely by recording in a ledger. In order to simplify the process of ordering the use of the futsal field, a study was made to create a Futsal Booking Information System on the futsal KAO using data collection methods carried out by observation, literature study, and interviews. The system analysis method uses SWOT analysis. The design of this program is made using UML containing use case diagrams, activity diagrams and sequence diagrams as design tools, by using the PHP program language (hypertext preprocessor) based on the Codeigniter framework and MYSQL as a database using the Agile Method as a system development method (SDLC). The method for testing used blackbox testing. This futsal field rental information system is expected to make it easier for customers and futsal field managers in the process of managing the futsal field usage schedule.
\end{abstract}

Keywords—booking, futsal, SDLC, agile.

\section{PENDAHULUAN}

Aplikasi berbasis web yang berkembang pada saat ini dapat diakses dengan menggunakan komputer, laptop bahkan smartphone sebagai media yang akan memberikan kemudahan kepada para penggunanya untuk mendapatkan informasi ataupun data yang diinginkan dengan mudah,

Vol.7 No.1 - Februari 2021 
cepat dan dapat diakses dimana saja dan kapan saja. Pengolahan data yang tepat dapat menghasilkan informasi yang baik dan menguntungkan untuk suatu organisasi, Lembaga apalagi yang berhubungan bisnis.Salah satu contohnya yaitu sistem penjadwalan penyewaan lapangan futsal.

Proses bisnis penyewaan lapangan futsal pada KAO futsal masih manual dengan mencatat proses sewa lapangan kedalam buku besar, sehingga untuk para pelanggan yang ingin bermain futsal dengan menyewa lapangan futsal harus datang ke tempat futsal secara langsung untuk mengatur waktu dan jadwal bermain futsal karena tanpa melakukan pengecekan secara langsung pelanggan tidak dapat mengetahui jadwal dan waktu bermain futsal yang masih kosong dan hal tersebut juga dapat menyebabkan terjadinya kesalahan dalam pengecekan karena proses bisnis yang masih manual pada buku pesanan.

Dengan dirancangnya sebuah aplikasi booking futsal dapat menjadi efisien dalam input data pemesanan, data penjadwalan dapat menghemat waktu tanpa mencatat manual di setiap pemesanan lapangan futsal. Dapat menyediakan data pemesanan lapangan futsal sesuai dengan kebutuhan pengguna lapangan futsal.Dapat merancang aplikasi booking futsal yang efisien, bermanfaat bagi KAO futsal serta tidak mencatat ulang lagi.

\section{METODE PENELITIAN}

Metode Penelitian yang akan dibahas dalam penelitian ini terdapat 5 metode, diantaranya adalah metode pengumpulan data, metode Analisa sistem, metode perancangan sistem, metode pengembangan sistem dan metode pengujian sistem.

\subsection{Pengumpulan Data}

Untuk mendapatkan data dan keterangan yang diperlukan dalam penelitian ini digunakan beberapa metode adalah sebagai berikut:

1. Metode observasi

Merupakan metode pengumpulan data melalui pengamatan langsung pada KAO Futsal JL.Sawah Darat, Kelurahan Ketapang, Kecamatan Cipondoh, Kota Tangerang, Provinsi Banten. Kode Pos 15147

\section{Metode wawancara}

Pada metode ini penulis melakukan proses tanya jawab kepada stakeholder pada objek penelitian Kao futsal Dalam hal ini proses tanya jawab dilakukan langsung kepada pengurus usaha yaitu Alwi Shihab .

3. Studi pustaka

Studi Pustaka adalah mencari sebuah informasi yang berkaitan dengan laporan tentang permasalahan yang dilakukan oleh peneliti. Informasi yang didapatkan berasal dari buku, jurnal, internet serta sumber sumber lainnya .

\subsection{Metode Analisa Sistem}

Metode analisa sistem yang digunakan pada penelitian ini adalah menggunakan metode analisa SWOT, yaitu menganalisa tentang dirancangnya pemesanan lapangan futsal pada KAO Futsal adapun yang dibahas dalam analisa SWOT tersebut diantaranya menganalisa kekuatan (strength), kelemahan (weakness), peluang (opportunity), dan ancaman (threat) dari Aplikasi booking futsal pada KAO futsal Dengan melakukan analisa SWOT, maka akan diketahui metode yang digunakan agar mencapai dengan tujuan serta manfaat pada KAO futsal.

\subsection{Metode Perancangan}

Metode Perancangan Sistem Booking Futsal Berbasis web pada KAO Futsal adalah menggunakan program program Visual Paradigm for UML 16.0. Enterprise Edition yaitu sebuah bahasa yang berdasarkan grafik yang dibutuhkan untuk merancang use case diagram, sequence diagram, activity diagram. Proses membuat program dan databasenya menyesuaikan 
berdasarkan permintaan dan kebutuhan stakeholder yang ada pada daftar elisitasi. Program yang digunakan dalam perancangan sistem menggunakan PHP sebagai bahasa pemrograman, MySQL sebagai database dan XAMPP sebagai web servernya[1].

\subsection{Metode Pengembangan Agile}

Metode yang digunakan dalam penelitian ini sebagai metode SDLC (Software Development Life Cycle)[2] adalah metode agile karena agile model pengembangan dengan jangka waktu pendek yang dapat beradaptasi dengan cepat. Pengembangan model ini bersifat dinamis terhadap perubahan dalam bentuk apapun, maka selama proses pengerjaanya programmer akan mengalami proses pengembangan yang berulang, karena setiap perulangan tersebut menyesuaikan dengan kebutuhan atau permintaan user dan proses kegiatan ya wajib untuk dilakukan dalam pengembangan software itusendiri[3].

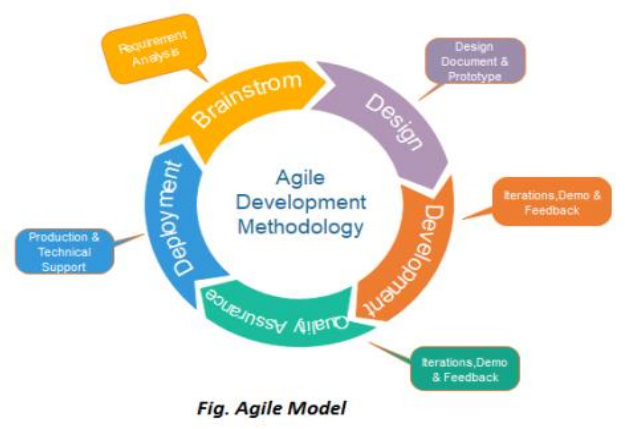

Gambar 1. Tahapan Metode Agile di dalam SDLC[1]

Berikut ini tahapan-tahapan dalam metode Agile:

1. Brainstorm, yaitu tahapan menganalisa Requirement.

2. Design, yaitu tahapan membuat desain prototype system dan mendokumentasikannya.

3. Development, yaitu tahapan coding kemudian menjalankan/demo system agar dapat melakukan perulangan dalam proses development jika masih terdapat kebutuhan yang belum terpenuhi oleh client.

4. Quality Assurance, yaitu tahapan perulangan dari tahapan coding kemudian menjalankan/demo system agar dapat melakukan perulangan dalam proses development jika masih terdapat kebutuhan yang belum terpenuhi oleh klien sampai dengan terpenuhi.

5. Deployment, yaitu tahapan menyelesaikan system dengan mengirimkan sistem kepada user karena semua aktivitas dalam membuat sebuah sistem perangkat lunak sudah dapat digunakan.

\subsection{Metode Pengujian}

Dalam melakukan perancangan berbasis website tersebut.Metode pengujian yang digunakan yaitu yaitu Blackbox Testing. Black Box Testing yaitu metode pengujian yang disesuaikan dengan kebutuhan fungsional terhadap software[4]. Oleh karena itu, Pengujian menggunakan blackbox menghasilkan pengembangan pada software tersebut untuk membuat himpunan kondisi sesuai dengan kondisi perancangan website tersebut dibuat.

\subsection{Literature Review}

1. Penelitian yang telah dilakukan oleh A. Haris, Wahanggara dan R.D. Yeni[1] (2017) yang berjudul "Implementasi Agile Model Pada Aplikasi Penyewaan Lapangan Futsal Berbasis Web Service".

2. Penelitian yang telah dijalankan oleh Maimunah[5], dkk (2017) yang berjudul "Rancang Bangun Sistem Aplikasi Penyewaan Lapangan Futsal Berbasis Web". 
3. Penelitian yang dilakukan oleh Rino Herningtyas Swastika dan Fata Nidaul Khasanah[6] (2017) yang berjudul "sistem informasi reservasi lapangan futsal pada futsal Corner menggunakan metode waterfall".

4. Penelitian yang telah dijalankan oleh Didit gunawan, Ernes cahyo Nugroho[7] (2015) yang berjudul "sistem informasi sewa rumah kost dan rumah kontrakan berbasis web di Surakarta".

5. Penelitian ini dilakukan oleh Intan septavia[8], dkk (2015) yang berjudul "Sistem informasi penyewaan mobil berbasis web di jasa karunia tour and travel".

6. Penelitian yang telah dilakukan oleh Aji Pujohardianto dan Syahbaniar Rofiah[9] (2019) dengan judul "Sistem Informasi Pemesanan Tiket Pesawat dengan Codeigniter dan Bootstrap".

\section{HASIL DAN PEMBAHASAN}

3.1 Rancangan UML (Unified Modeling Language) Sistem

Berikut ini terdapat 3 jenis Diagram yang akan dipaparkan yaitu usecase diagram, activity diagram dan sequence diagram.

1. Use Case Diagram

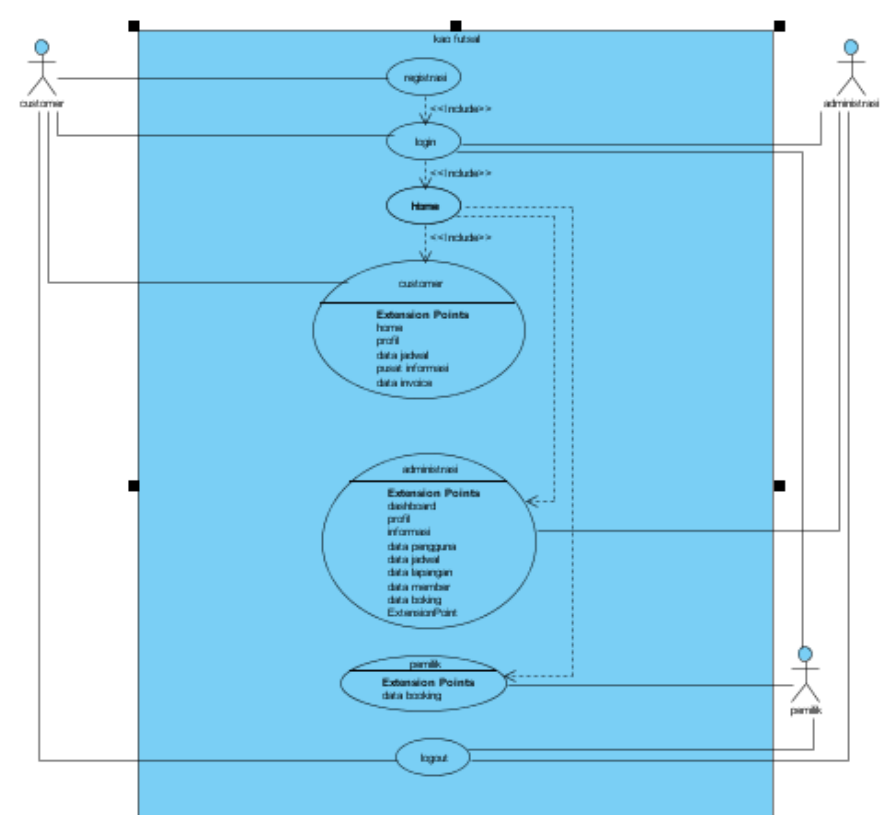

Gambar 2.Use Case diagram sistem yang diusulkan

Berdasarkan gambar use case yang diusulkan diagram penyewaan lapangan futsal terdapat :

1. Terdapat satu sistem yang mencakup seluruh kegiatan sistem informasi Booking Futsal Berbasis Web.

2. Terdapat 3 aktor yang melakukan kegiatan yaitu customer, Administrasi, Pemilik.

3. Terdapat 7 use case yaitu registrasi, login, home, customer, administrasi, pemilik, logout.

4. Terdapat 14 extend yaitu, home, profil, data jadwal, dashboard, profil, informasi, data pengguna, data jadwal, data lapangan, data member, data booking, data booking

2. Activity Diagram Customer 


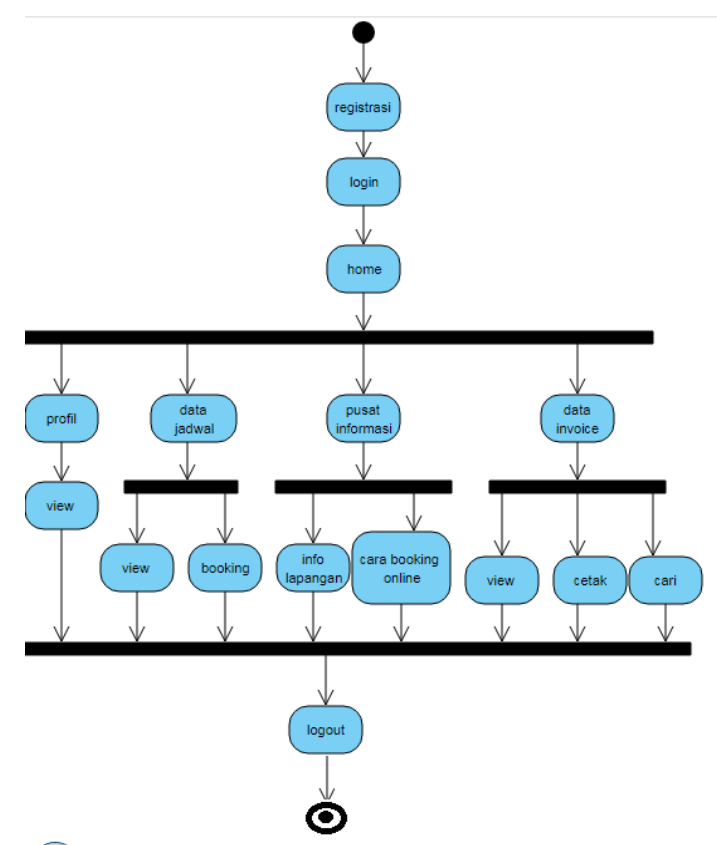

Gambar 3.Activity Diagram Customer yang Diusulkan

Berdasarkan gambar activity diagram customer yang diusulkan terdapat :

1. Satu initial node, yang mengawali objek

2. Terdapat lima fork node untuk memecahkan action

3. Lima belas action state, yaitu menggambarkan eksekusi kegiatan.

4. Satu final node, yang mengakhiri objek

3. Activity Diagram Admin

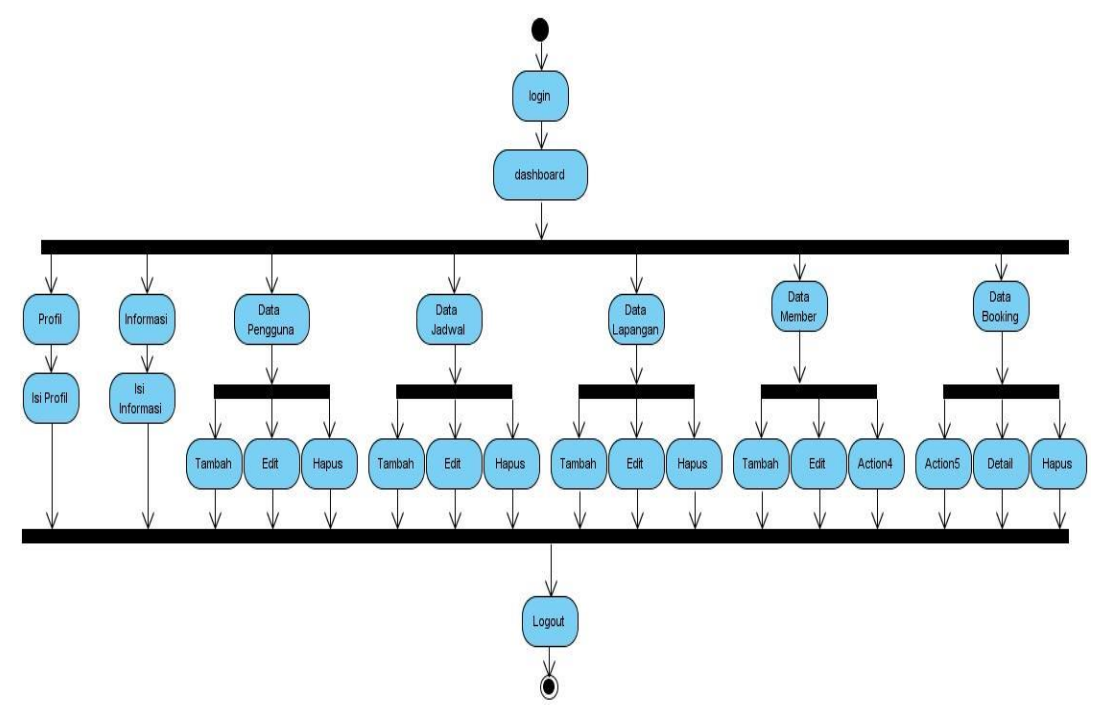

Gambar 4.Activity Diagram Administrasi yang Diusulkan

Berdasarkan gambar activity diagram admin yang diusulkan terdapat :

1. Satu initial node, yang mengawali objek

2. Terdapat tujuh fork node untuk memecah action

3. Dua puluh tujuh action state, yaitu menggambarkan eksekusi kegiatan.

4. Satu final node, yang mengakhiri objek 
4. Sequence Diagram Customer

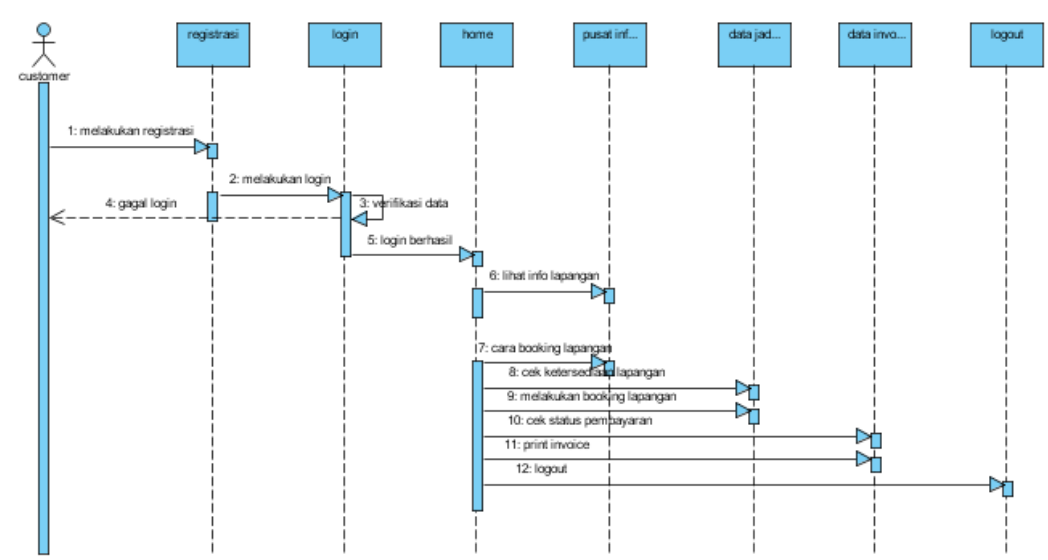

Gambar 5.Sequence DiagramCustomeryang Diusulkan

Berdasarkan gambar sequence diagram Customer yang diusulkan terdapat :

1. Satu actor yang melakukan kegiatan, yaitu customer

2. Dua belas message yang dapat menjadi alat komunikasi antar objek yang memuat informasi-informasi tentang kegiatan yang terjadi.

3. Satu Self message verifikasi data.

4. $\quad$ Satu return message gagal login.

5. Tujuh life line yang saling berinteraksi.

5. Sequence Diagram Admin

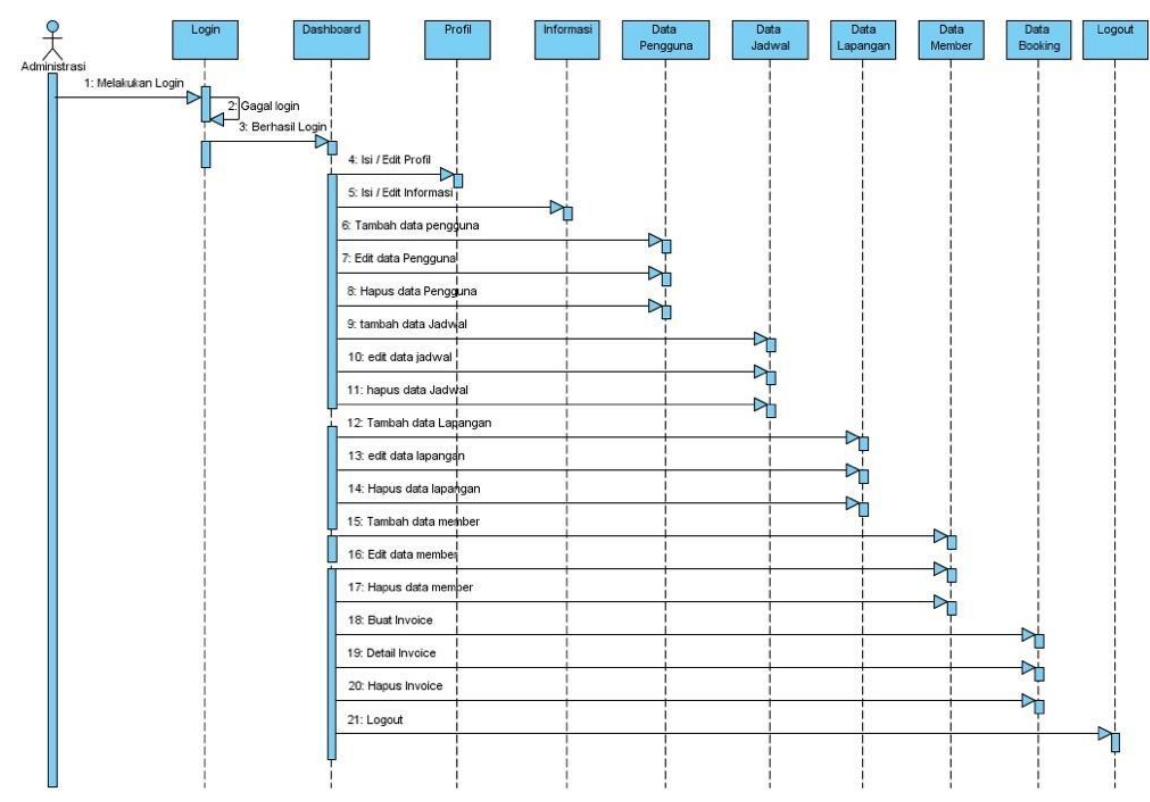

Gambar 6.Sequence Diagram Administrasiyang Diusulkan

Berdasarkan gambar sequence diagram administrasi yang diusulkan terdapat :

1. Satu actor yang melakukan kegiatan, yaitu admin

2. Dua puluh message yang dapat menjadi alat komunikasi antar objek yang memuat informasi-informasi tentang kegiatan yang terjadi.

3. Satu self message gagal login. 
4. Sepuluh life line yang saling berinteraksi

\subsection{Rancangan Class Diagram}

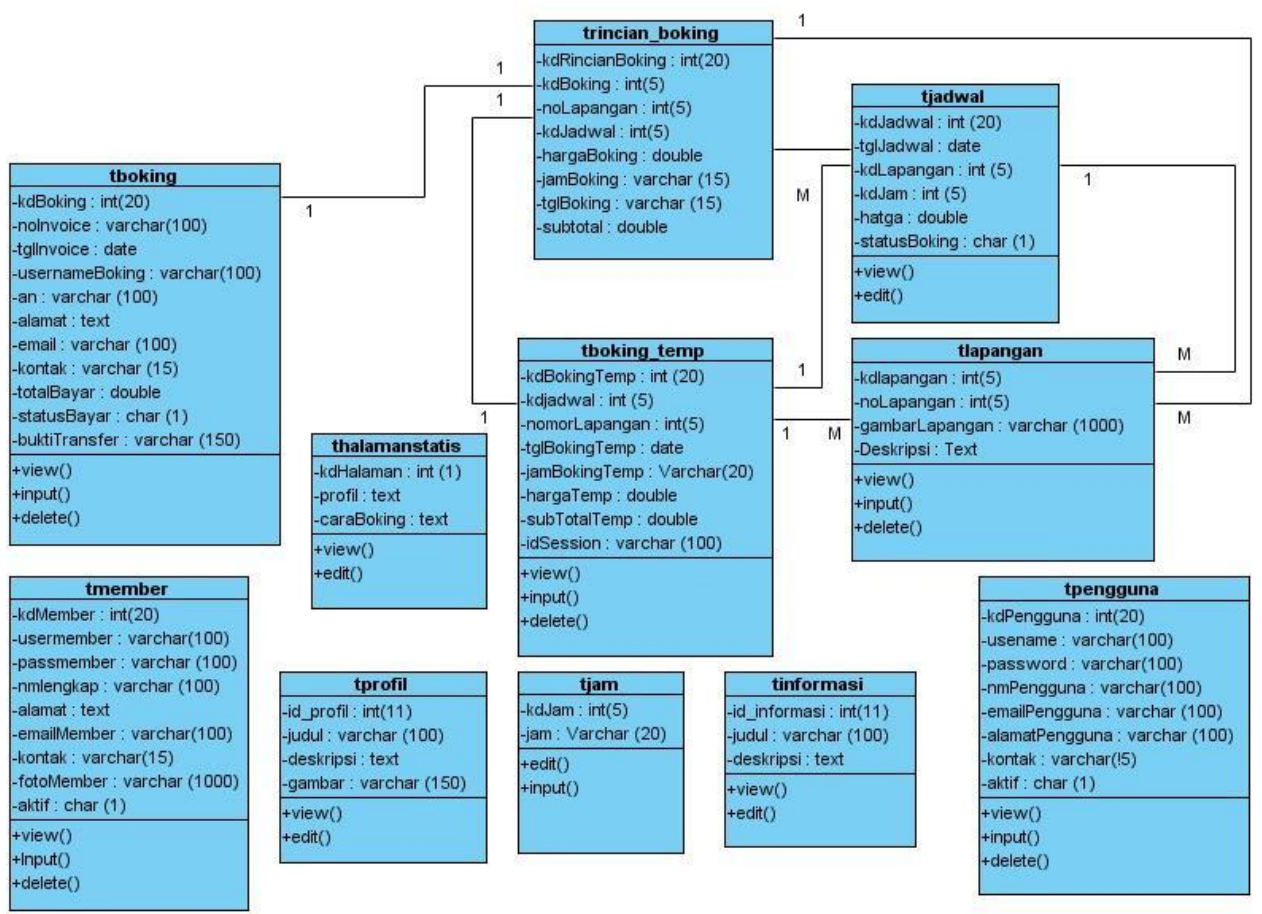

Gambar 7.Class Diagram yang Diusulkan

Berdasarkan gambar class diagram yang diusulkan terdapat :

1. Sebelas Class, himpunan dari atribut dan operasi yang saling berhubunga

2. Tujuh multiplicity, hubungan antara class satu dengan yang lainnya.

3.3 Design Tampilan Sistem

1. Tampilan Halaman Utama Customer

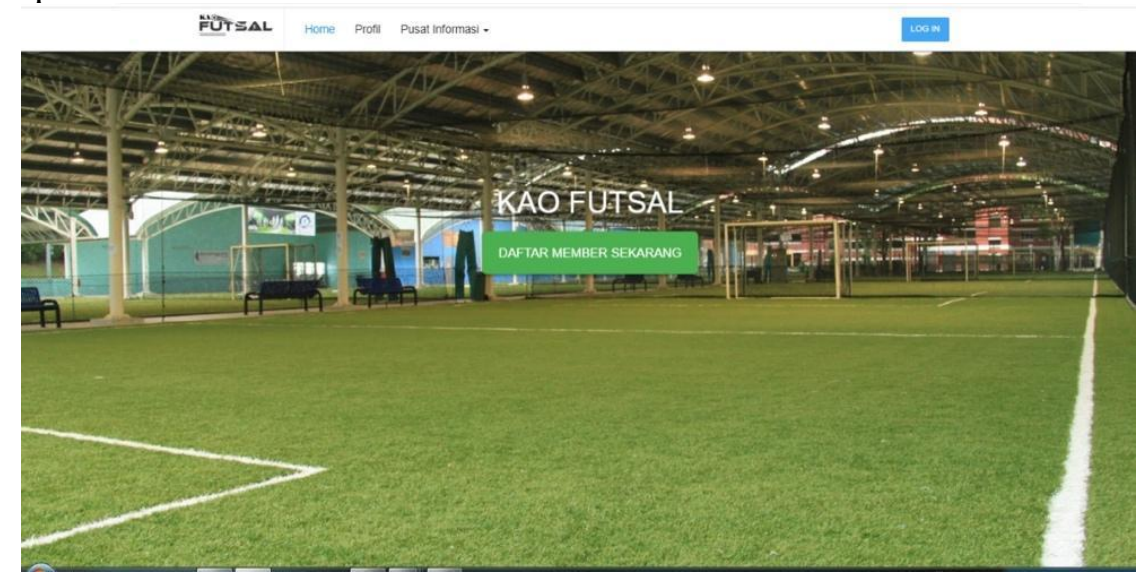

Gambar 8.Tampilan Halaman Utama Customer

2. Tampilan Menu Registrasi 


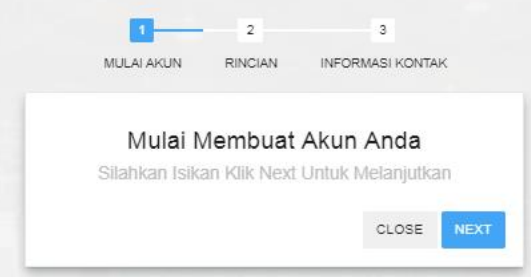

Gambar 9.Tampilan Menu Registrasi

3. Tampilan Menu Login Customers

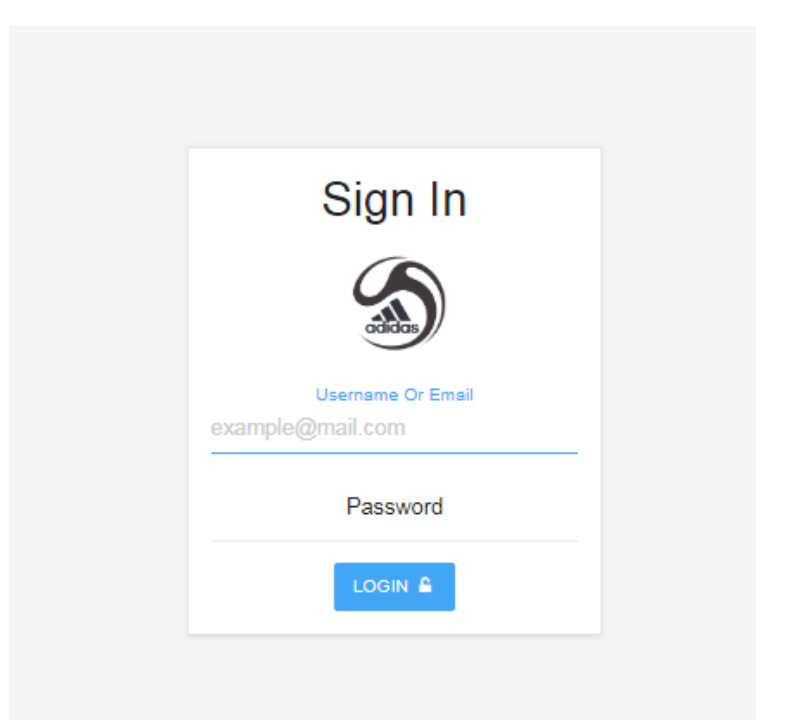

Gambar 10.Tampilan Menu Login Customers

4. Tampilan Menu daftar jadwal

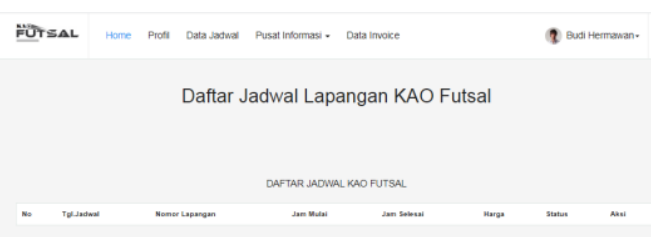

Gambar 11. Tampilan Menu daftar jadwal

5. Tampilan Menu Cara Pesan Lapangan 


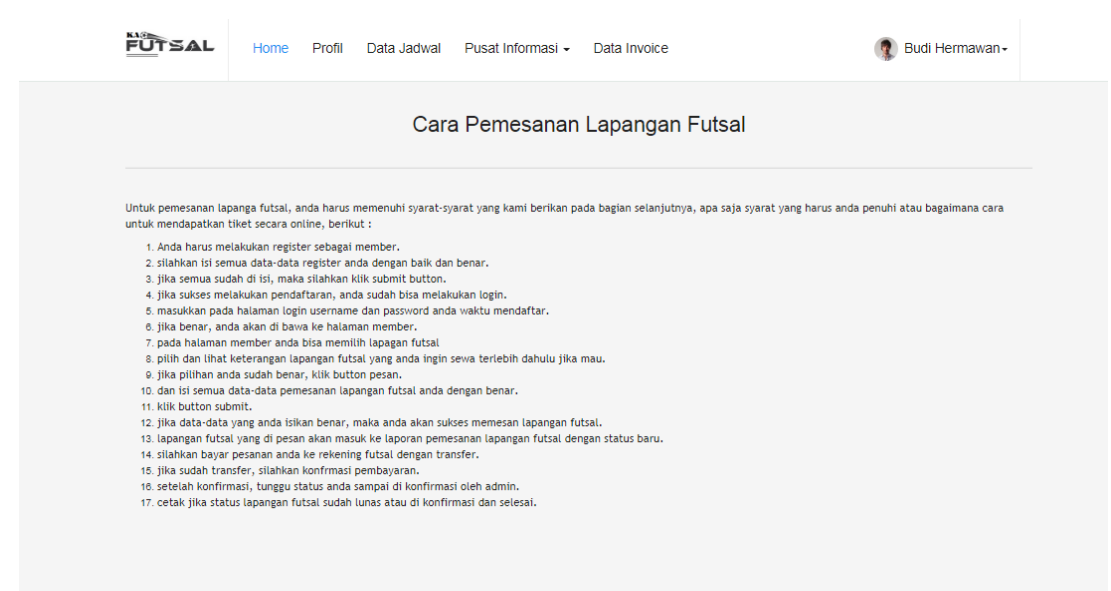

Gambar 12. Tampilan menu cara pesan lapangan

6. Tampilan Menu Data Invoice

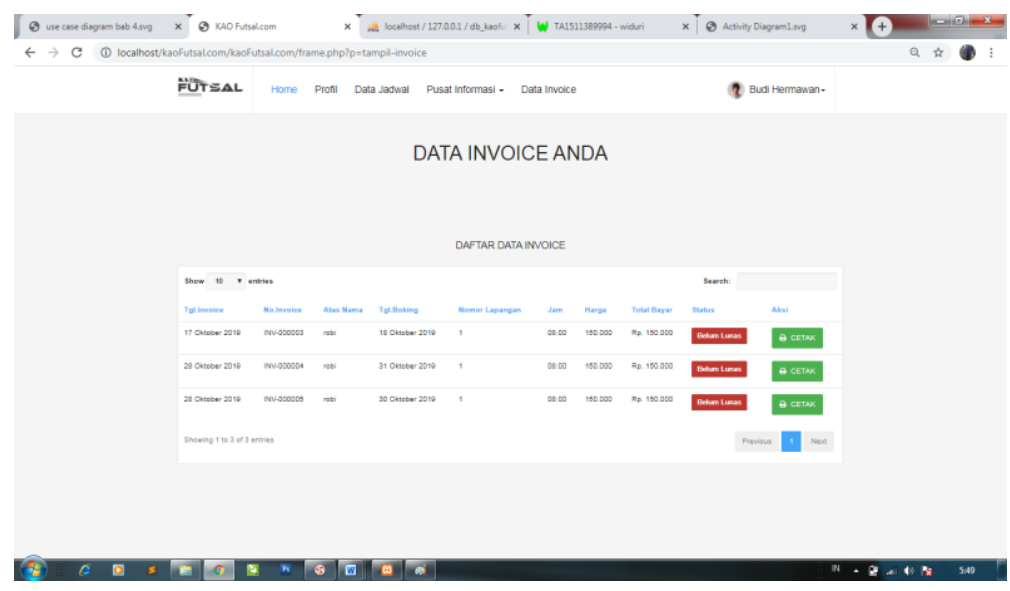

Gambar 13. Tampilan Menu Data Invoice

7. Tampilan Menu login administrasi

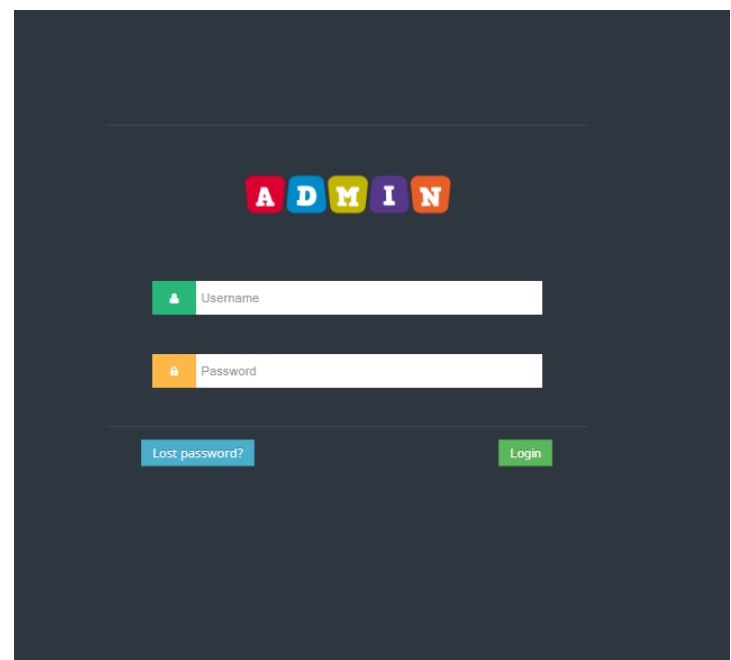

Gambar 14. Tampilan Menu login administrasi

8. Tampilan Menu Dashboard Administrasi 


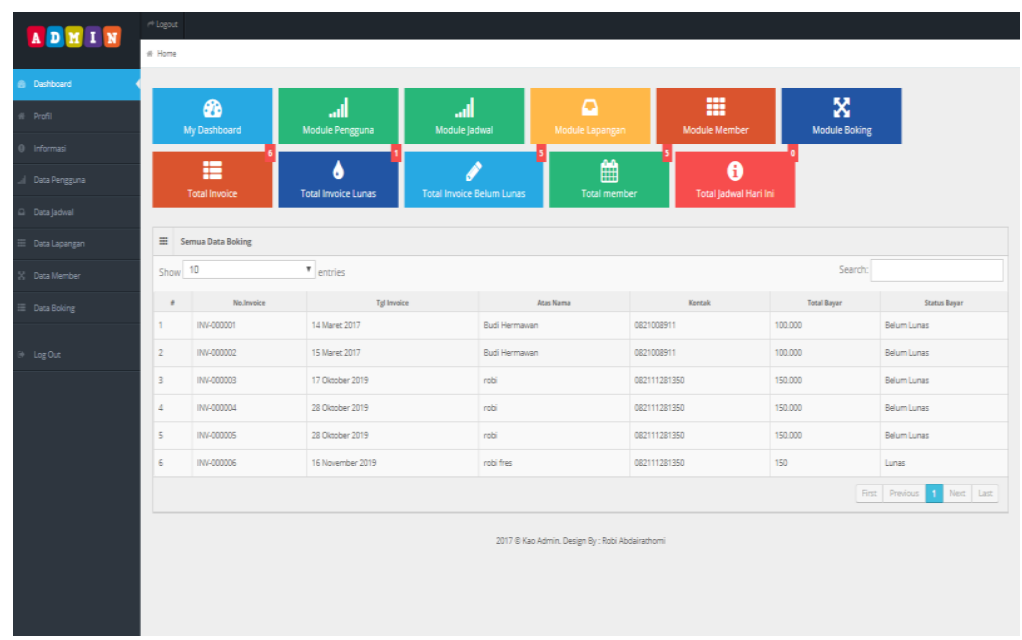

Gambar 15. Tampilan Menu Dashboar Administrasi

9. Tampilan Menu Data Jadwal (administrasi)

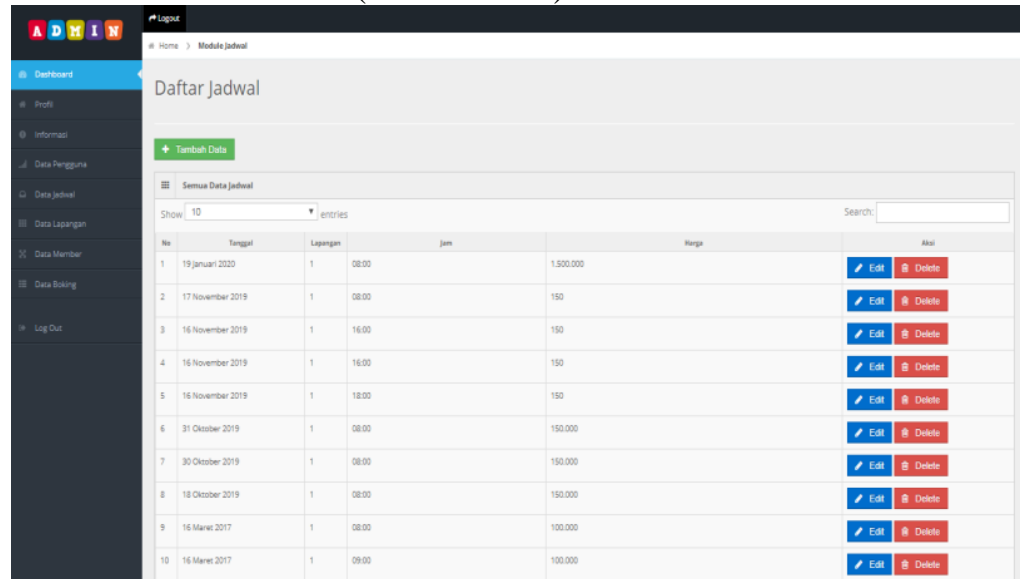

Gambar 16. Tampilan Data Jadwal (administrasi)

10. Tampilan Menu Data Member (administrasi)

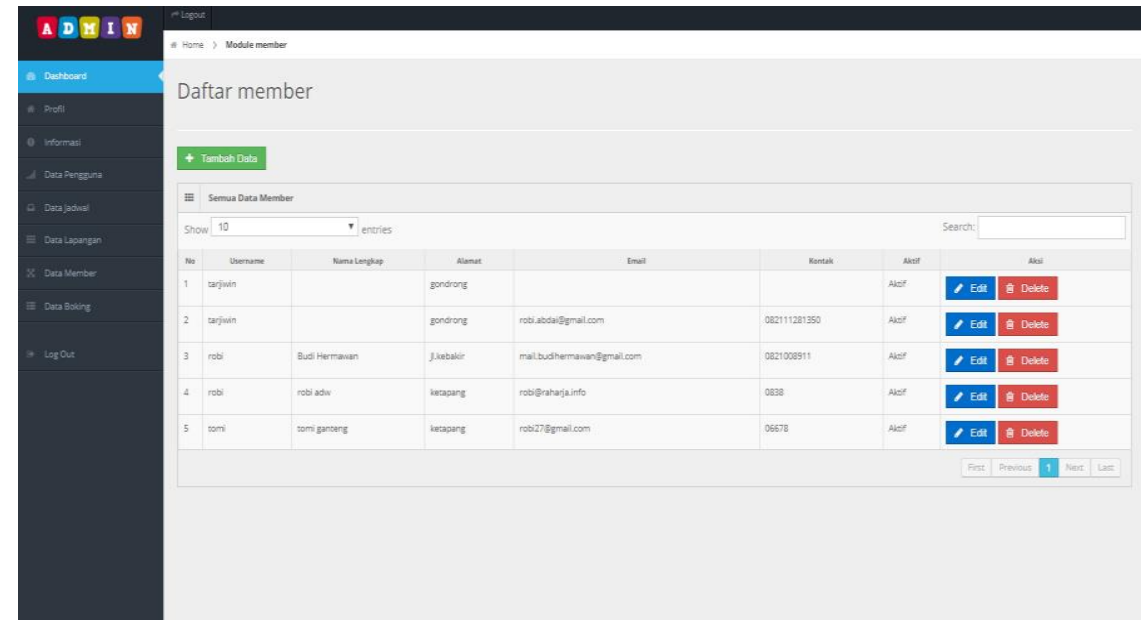

Gambar 17. Tampilan Menu Data Member (administrasi)

11. Tampilan Menu Data Boking (administrasi) 


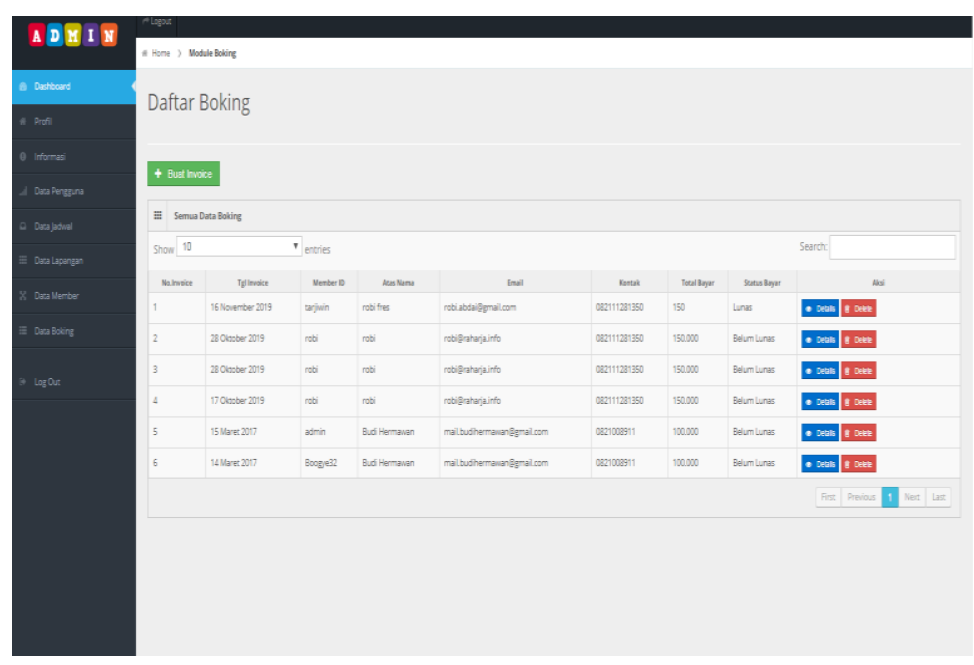

Gambar 18. Tampilan Menu Data Booking (administrasi)

\section{KESIMPULAN}

Berdasarkan hasil penelitian dan observasi yang dilakukan peneliti pada system penyewaan lapangan futsal pada KAO Futsal maka peneliti menarik kesimpulan sebagai berikut:

1. Sistem penyewaan lapangan futsal pada kao futsal yang berjalan pada saat ini masih belum terkomputerisasi apabila ingin melakukan penyewaan customer harus mendatangi langsung kelapangan.

2. Sistem penyewaan lapangan futsal pada kao futsal yang berjalan pada saat ini masih memiliki kelemahan dalam melakukan penyewaan dan pembuatan laporan masih dilakukan secara manual.

3. Dalam proses rancangan sitem booking futsal berbasis web pada kao futsal penulis menggunakan metode analisa dan perancangan berorientasi objek menggunakan UML (Unified Modeling Language), kemudian dibuat dengan menggunakan bahasa pemrograman PHP dan database Mysql. Dengan adanya sistem penyewaan lapangan futsal diharapkan dapat mempermudah melakukan proses penyewaan dan pencatatan laporan dapat lebih akurat dan cepat sehingga dapat mengurangi kesalahan pencatatan serta informasi data penyewaan dapat lebih akurat.

\section{SARAN}

Berdasarkan hasil penelitian dan analisis yang dilakukan oleh peneliti mengenai sistem penyewaan lapangan futsal pada KAO Futsal maka terdapat beberapa saran yang dapat dijadikan masukkan untuk meningkatkan kinerja, yaitu sebagai berikut:

1. Melakukan pemeliharaan sistem secara berkala untuk menghindari kerusakan atau kesalahan program. Dan Untuk menghindari kehilangan data perlu dilakukan backup Data sebaiknya disimpan.

2. Melakukan pelatihan bagi pengguna dalam menggunakan sistem booking lapangan futsal agar sistem dapat dimanfaatkan secara maksimal.

3. Melakukan pengembangan sistem mengikuti perkembangan teknologi kedepannya seperti membuat aplikasi Android agar mempermudah. 
[1] V. Wahanggara, S. Kom, M. K. Yeni, D. Rahayu, S. St, and M. Kom, "Implementasi Agile Model Pada Aplikasi Penyewaan Lapangan Futsal Berbasis Web Service". Universitas Muhammadiyah Jember, 12 Jul 2018.

[2] R. Ilyas and Y. H. Chisnanto, "Pengembangan Sistem Informasi Penelitian LPPM Universitas Jenderal Achmad Yani Dengan Agile SDLC," pp. 8-9, 2018.

[3] F. Nurzaman, "Pengembangan Sistem Otomatisasi Tagihan Menggunakan Metode Agile Software," vol. 4, no. 1, pp. 46-57, 2020.

[4] R. Rian, C. Putra, and D. Y. Sylfania, "Aplikasi Pemesanan Tiket Bioskop Berbasis Android Pada Bes Cinema Pangkalpinang," vol. 6, no. 2, pp. 196-206, 2018.

[5] G. Jihadi, "Rancang Bangun Sistem Aplikasi Penyewaan Lapangan,” pp. 7-12, 2017.

[6] R. H. Swastika and F. N. Khasanah, "Sistem Informasi Reservasi Lapangan Futsal Pada Futsal Corner Menggunakan Metode Waterfall," vol. 1, no. 2, pp. 251-266, 2017.

[7] D. Gunawan and E. C. Nugroho, "Sistem informasi sewa rumah kost dan rumah kontrakan berbasis web di surakarta," vol. 2, no. 1, pp. 19-25, 2015.

[8] I. Septavia, R. E. Gunadhi, and R. Kurniawati, "Sistem Informasi Penyewaan Mobil Berbasis Web," pp. 534-540, 2005.

[9] A. Pujohardiyanto and S. Rofiah, "Sistem Informasi Pemesanan Tiket Pesawat dengan Codeigniter dan Bootstrap," vol. 6, no. 1, pp. 103-112, 2019. 